
\title{
25 Research Square \\ Effect of Metal Oxides and Graphene Upon The Electronic Properties of Polyvinyl Alcohol
}

\author{
Maroof A. Hegazy \\ NRIAG \\ Hend A. Ezzat \\ NRIAG \\ Ibrahim S. Yahia \\ King Khaled University \\ Heba Y. Zahran \\ King Khaled University \\ Hanan Elhaes \\ Ain Shams University \\ Hanan Matar \\ BUE: The British University in Egypt \\ Medhat Ibrahim ( $\sim$ medahmed6@yahoo.com ) \\ NRC., Egypt https://orcid.org/0000-0002-9698-0837
}

\section{Research Article}

Keywords: PVA, HOMO/LUMO, MESP, GQD and Humidity Sensor

Posted Date: November 8th, 2021

DOI: https://doi.org/10.21203/rs.3.rs-990839/v1

License: (c) (i) This work is licensed under a Creative Commons Attribution 4.0 International License.

Read Full License 


\section{Abstract}

Nanomaterials improve the physical and electronic characteristics of polymer matrices, allowing the matrices to be used as low cost, easy to handle sensors. Nano $\mathrm{ZnO}$ oxide is forming nanocomposite with PVA modified with graphene. Rather than $\mathrm{ZnO}$ other metal oxides are assumed to enhance the electronic properties of PVA modified with graphene (G). Accordingly, Density Function Theory (DFT) was used to analyze model molecules of Polyvinyl Alcohol (PVA) that improved with various metal oxides and graphene quantum dots (GQDs). To show the influence of nanomaterials on PVA matrix behavior, HOMO/LUMO molecular orbitals and Molecular Electrostatic Potential (MESP) mapping were calculated. The B3LYPL/LAN2DZ model was used to calculate the band gap energy $\Delta \mathrm{E}$, total dipole moment (TDM), and Molecular Electrostatic Potential (MESP). The obtained results indicated that PVA interacted with $\mathrm{MgO}$, led to a significant improvement in the electrical characteristics. The incorporation of GQDs into PVA/MgO resulted in a novel nanocomposite with good electrical characteristics and a band gap energy $\Delta \mathrm{E}$ of $0.201 \mathrm{eV}$, which is intended to be used as a humidity sensor.

\section{1- Introduction:}

Synthetic polymers are gaining popularity in a variety of technical applications [1]. PVA is one of the most significant synthetic polymers that is frequently utilized among a variety of conducting and nonconducting polymers due to its availability in high molecular mass, good water solubility and low price [2]. It is also non-toxic, biocompatible, and biodegradable, with strong chemical resistance and outstanding optical, electrical, and thermal characteristics [3]. PVA's exceptional characteristics make it a perfect option for a wide range of applications, including biomedical devices, drug delivery, membrane technology [4], fuel cells, solar cells [5], optical devices [6] and sensors. According to the high surface area of the nanofillers, such as metal oxides, different nanofillers are typically used to improve the characteristics of PVA [7]. The elastic modulus of $\mathrm{PVA} / \mathrm{ZrO}_{2}$ sample was around 5.5 times greater than pure PVA after PVA was reinforced with varied ratios of $\mathrm{ZrO}_{2}$ nanoparticles [8]. The findings demonstrate also that the $\mathrm{PVA} / \mathrm{Fe}_{3} \mathrm{O}_{4}$ flexible magnetic tape is an interesting possibility for applications in biomedicine and biosensors [9]. PVA-polyethylene oxide (PEO)/ $\mathrm{SnO}_{2}$ nanocomposites also improved PVA's electrical and optical characteristics, indicating that they could be applied in optoelectronics [10]. In addition, the structural and optical characteristics of PVA/PEO/CuO nanocomposites were studied for humidity sensor applications [11]. The dielectric constant, dielectric loss, AC electrical conductivity, and absorbance of the PVA/PEO mix doped with various concentrations of MgO nanoparticles increased with increasing concentrations of $\mathrm{MgO}$ nanoparticles [12]. Molecular modeling is theoretical approach used for investigating chemical problems such as molecular geometries [13, 14], infrared ray (IR) [15], molecule energies [16], and structures physical characteristics [17]. There are a variety of molecular modelling methods for studying physical and chemical characteristics of materials, which are frequently utilized in organometallic and transition metal chemistry $[18,19]$. In recent years, DFT is considered the best solution for quantum mechanical simulation; which is now widely utilized for molecular structure simulation models $[20,21]$. In certain situations, DFT provides better agreement with experimental results 
than other methods $[22,23]$. For the first time, both experimental and theoretical findings of new $\mathrm{PVA} / \mathrm{MgO} / \mathrm{SiC}$ nanocomposites on the structural and optical characteristics were investigated for low cost, high sensitivity, and flexibility humidity sensor [24]. Also, the results of electronic properties (total energy, cohesive energy, HOMO, LUMO, energy gap, electronegativity, and electrophilicity) and spectroscopic properties (IR, NMR, and UV) of PVA/PEO/SiC nanocomposite using DFT:B3LYP/LanL2DZ model showed that PVA/PEO/SiC could be used as optoelectronic material [25]. Furthermore, the implantation of GQDs in polymer metal oxide matrices, particularly $\mathrm{NiO}$, has outstanding properties that, provide materials suitable to apply in energy storage and sensing applications [26].

In this work, PVA is interacted with $\mathrm{G}$ as well as $\mathrm{ZnO}$ forming PVA/ZnO/G nanocomposite. To follow up the effect of $\mathrm{ZnO}$ as well as many other metal oxides on PVA molecular modeling is consulted.

Accordingly, PVA interactions with several metal oxides, including $\mathrm{MgO}, \mathrm{Al}_{2} \mathrm{O}_{3}, \mathrm{SiO}_{2}, \mathrm{TiO}_{2}, \mathrm{Fe}_{3} \mathrm{O}_{4}, \mathrm{NiO}, \mathrm{CuO}$, $\mathrm{ZnO}$, and $\mathrm{ZrO}_{2}$ electronic characteristics supposed to study using DFT calculations. HOMO/LUMO orbital distributions and MESP mapping calculations for all model structures. Also, effect of GQDs on the PVA/MO composite electronic characteristics were studied using the same theory to be used as humidity sensor.

\section{2- Material And Methods:}

All chemicals were used without any further purification. Zinc (II) acetate dihydrate (Fisher chemical, 99 \%), Polyvinyl alcohol (sigma aldrich, Mwt 85000 - 124000, 87-89\%), Sodium hydroxide (Fisher chemical, $\geq 97 \%$ ). The deionized (DI) Milli-Q water was used during this experiment.

\section{2-2 Synthesis of ZnO Nanoparticles:}

The ZnO nanoparticles were synthesized using the precipitation method. In a typical method; a solution of Zinc (II) acetate dihydrate $\left(1 \mathrm{M}, 100 \mathrm{ml}\right.$ DI water) was heated to $70^{\circ} \mathrm{C}$ followed by dropwise addition of a solution of Sodium hydroxide ( $2 \mathrm{M}, 100 \mathrm{~mL}$ DI water) with stirring. After cooling down to room temperature, the precipitate was separated by centrifugation at $10000 \mathrm{rpm}$, washed several times with DI water, then dried in an oven overnight at $80^{\circ} \mathrm{C}$, and finally calcined at $500^{\circ} \mathrm{C}$ for $2 \mathrm{~h}$.

\section{2-3 Preparation of PVA/ZnO/G Membrane:}

The as-prepared ZnO $(0.01 \mathrm{gm})$ and $\mathrm{G}$ sheets $(0.02 \mathrm{gm})$ were mixed in $100 \mathrm{ml}$ PVA solution (70\%) with stirring till obtain a homogeneous solution, then added in petri dishes to dry in air.

\section{2-4 Characterization Techniques:}

The Attenuated Total Reflection Fourier Transform Infrared (ATR-FTIR) spectra were determined using a FTIR spectrometer (Vertex 70, Bruker); the spectra were recorded in a spectral range of $4000-400 \mathrm{~cm}^{-1}$ with a spectral resolution of $4 \mathrm{~cm}^{-1}$. 
The X-ray Diffraction (XRD) of the as-prepared ZnO and $\mathrm{G}$ samples were characterized using Malvern Panalytical Empyrean 3 diffractometer to determine the phase composition and crystal structure.

The morphology of the prepared samples was measured using Field-emission Scanning Electron Microscopy (FESEM, Quattro S, Thermo Scientific).

\section{2-5 Calculation Details:}

DFT calculations were performed on a model structure that simulated PVA interactions with several metal oxides, including $\mathrm{MgO}, \mathrm{Al}_{2} \mathrm{O}_{3}, \mathrm{SiO}_{2}, \mathrm{TiO}_{2}, \mathrm{Fe}_{3} \mathrm{O}_{4}, \mathrm{NiO}, \mathrm{CuO}, \mathrm{ZnO}$, and $\mathrm{ZrO}_{2}$. All models were computed using the GAUSSIAN09 [27] at Molecular Spectroscopy and Modeling unite, National Research Centre, Egypt. B3LYP/LANL2DZ model was utilized for structures calculations [28-30]. HOMO/LUMO orbital distribution, TDM, band gap and MESP mapping were calculated for all model structures for studying electronic properties.

\section{3- Result And Discussion:}

\section{3-1 Experimental Result of PVA/ZnO/G Composite:}

Nano $\mathrm{ZnO}$ as well as $\mathrm{G}$ is assumed to interact with PVA matrix. The interaction is first tested by means of FTIR. Figure1 presented the ATR-FTIR transmittance spectra for the studied PVA, ZnO, G and PVA/ZnO/G nanocomposite. Actually, the overall aim not to assign each structure but to have a look to $\mathrm{PVA} / \mathrm{ZnO} / \mathrm{G}$ nanocomposite. The spectra of PVA/ZnO/G nanocomposite confirm the occurrence of composite between PVA; ZnO and G. The ATR-FTIR spectra of PVA/ZnO/G nanocomposite illustrate that the characteristic peak of the utilized metal oxide appears at $500 \mathrm{~cm}^{-1}$ that insures the presence of the $\mathrm{ZnO}$ in the composite. Moreover, the characteristic $\mathrm{C}=\mathrm{C}$ peak of the $\mathrm{G}$ sheets in the composite is still defined at $1550 \mathrm{~cm}^{-1}$. The band at $1575 \mathrm{~cm}^{-1}$ present in the composite confirmed that $\mathrm{ZnO}$ interacted through acetate as stated earlier [31]. The nanocomposites were further investigated with XRD diffraction to study the nature of crystallinity of the samples. The X-ray diffraction pattern of the PVA/ZnO/G nanocomposite powder in comparison with the pure PVA; ZnO and Graphene are indicated in figure 2. A broad intense peak appeared at the scattering angle of $2 \theta=19.7^{\circ}$ related to the ' $d^{\prime}$ ' spacing of $4.48 \AA$ which can be attributed to the (-101) reflection plane of the crystalline PVA [32-33]. The crystalline nature of PVA can be attributed to the strong interaction between the PVA chains through intermolecular hydrogen bonding. The XRD pattern of $\mathrm{ZnO}$ nanoparticles describes the hexagonal wurtzite structure, the crystalline peaks appeared around $2 \theta=31.72^{\circ}, 34.37^{\circ}, 36.21^{\circ}, 47.49^{\circ}, 56.55^{\circ}, 62.80^{\circ}, 66.34^{\circ}, 67.92^{\circ}$ and $69.06^{\circ}$ which can be attributed to (100), (002), (101), (102), (110), (103), (200), (112) and (201), respectively the reflection planes pertaining to the hexagonal phase of $\mathrm{ZnO}$ as stated earlier [34-35].

Figure 3 presented the surface morphological changes on the PVA surface because of interaction with both $\mathrm{ZnO}$ as well as $\mathrm{G}$. FESEM of PVA, ZnO, G and PVA/ZnO/G powder samples. It is clear that ZnO exhibits aggregated and randomly distribution the on top of PVA surface. While $G$ show further enhancing for the surface of PVA as indicated in the nanocomposite. 
In order to investigate the effect of $\mathrm{G}$ as well as $\mathrm{ZnO}$ on the electronic properties and possible applications of their nanocomposite molecular modeling were consulted. The overall aim to follow up the effect of different metal oxides on the electronic properties of PVA in the existence of G.

\section{3-2 Building Model Molecule:}

Polymeric nanocomposite has lately grabbed the attention of scientists due to its wide range of uses. The nanofillers into the polymer matrix improves the polymer matrix's main features, leading to an improvement electrical and optical mechanical properties [36]. Accordingly, model structure postulate 4 monomers of PVA interactions with several metal oxides, including $\mathrm{MgO}, \mathrm{Al}_{2} \mathrm{O}_{3}, \mathrm{SiO}_{2}, \mathrm{TiO}_{2}, \mathrm{Fe}_{3} \mathrm{O}_{4}, \mathrm{NiO}$, $\mathrm{CuO}, \mathrm{ZnO}$, and $\mathrm{ZrO}_{2}$. The effect of $\mathrm{MO}$ composition on the electronic characteristics of PVA was studied by calculating HOMO/LUMO orbital distributions and MESP mapping calculations for all model structures. Furthermore, due to the high surface-to-volume ratio of GQDs, the edge atoms have an excellent contact with the surrounding molecules [37]. Besides, the bandgap tuning characteristic and electron transport ability of GQDs with a change in size may be applied in sensing [38].

So, GQD four forms ATRI, AHEX, ZTRI, and ZHEX were supposed to interact with the best enhanced structure of PVA/MO. PVA/MO/GQD postulated structures were studied also by calculating HOMO/LUMO orbital distributions and MESP mapping to be applied as humidity sensor.

\section{3-1 Interaction of PVA with Different Metal Oxides: HOMO/LUMO Orbital Distribution}

The supposed structures of the PVA 4 monomers interactions with several metal oxides, including MgO, $\mathrm{Al}_{2} \mathrm{O}_{3}, \mathrm{SiO}_{2}, \mathrm{TiO}_{2}, \mathrm{Fe}_{3} \mathrm{O}_{4}, \mathrm{NiO}, \mathrm{CuO}, \mathrm{ZnO}$, and $\mathrm{ZrO}_{2}$ and calculating $\mathrm{HOMO} / \mathrm{LUMO}$ orbital distributions illustrated in figure (4). For 4 PVA monomers HOMO/LUMO orbital dispersion is distributed over all chain. In the presence of MOs interactions HOMO/LUMO orbitals were rearranged and localized around the MO. Table (1) introduce calculated TDM and band gap energy $(\Delta \mathrm{E})$ of all structures. TDM of all MOs with PVA increased from 06.434 Debye to 29.420, 11.506, 15.823, 07.645, 09.481, 07.158, 08.512, 18.691, 12.910, 18.073, 07.977, 25.064 and 13.288 for $\mathrm{MgO}, \mathrm{OMg}, \mathrm{Al}_{2} \mathrm{O}_{3}, \mathrm{O}_{3} \mathrm{Al}_{2}, \mathrm{SiO}_{2}, \mathrm{TiO}_{2}, \mathrm{Fe}_{3} \mathrm{O}_{4}, \mathrm{NiO}, \mathrm{ONi}, \mathrm{CuO}, \mathrm{OCu}, \mathrm{ZnO}$ and $\mathrm{OZn}$, respectively, except in case of $\mathrm{ZrO}_{2}$ the TDM decreased to 05.607 Debye. At the same time, band gap energy $(\Delta E)$ of all MOs with PVA decreased from $6.989 \mathrm{eV}$ to $0.330,0.358,1.291,0.529,0.788$, $0.796,1.289,1.194,0.626,1.030,1.076,0.413,0.394$ and 0.904 for $\mathrm{MgO}, \mathrm{OMg}, \mathrm{Al}_{2} \mathrm{O}_{3}, \mathrm{O}_{3} \mathrm{Al}_{2}, \mathrm{SiO}_{2}, \mathrm{TiO}_{2}$, $\mathrm{Fe}_{3} \mathrm{O}_{4}, \mathrm{NiO}, \mathrm{ONi}, \mathrm{CuO}, \mathrm{OCu}, \mathrm{ZnO}, \mathrm{OZn}$ and $\mathrm{ZrO}_{2}$, respectively. Because of rising TDM with decreasing band gap energy $(\triangle \mathrm{E})$, the electronic characteristics improved, and the structure became more stable. As a result, $\mathrm{PVA} / \mathrm{MgO}$ is the most electronic improved and stable structure. 
Table 1

Optimised TDM (Debye) and $\triangle \mathrm{E}(\mathrm{eV})$ using B3LYP/LANL2DZ for PVA and PVA interacted with different metal oxides

\begin{tabular}{|c|c|c|}
\hline Structure & TDM (Debye) & $\Delta \mathrm{E}(\mathrm{eV})$ \\
\hline PVA & 06.434 & 6.989 \\
\hline PVA/MgO & 29.420 & 0.330 \\
\hline PVA/OMg & 11.506 & 0.358 \\
\hline $\mathrm{PVA} / \mathrm{Al}_{2} \mathrm{O}_{3}$ & 15.823 & 1.291 \\
\hline $\mathrm{PVA} / \mathrm{O}_{3} \mathrm{Al}_{2}$ & 07.645 & 0.529 \\
\hline PVA/OSiO & 09.481 & 0.788 \\
\hline PVA/OTIO & 07.158 & 0.796 \\
\hline $\mathrm{PVA} / \mathrm{Fe}_{3} \mathrm{O}_{4}$ & 08.512 & 1.289 \\
\hline PVA/NiO & 18.691 & 1.194 \\
\hline PVA/ONi & 12.910 & 0.626 \\
\hline PVA/CuO & 18.073 & 1.030 \\
\hline PVA/OCu & 07.977 & 1.076 \\
\hline PVA/ZnO & 25.064 & 0.413 \\
\hline PVA/OZn & 13.288 & 0.394 \\
\hline PVA/OZrO & 05.607 & 0.904 \\
\hline
\end{tabular}

\section{Molecular Electrostatic Potential (MESP):}

MESP is a significant tool for estimating the electrostatic interaction of a chemical system with other molecules. MESP was used to investigate the sensitivity of a chemical system to explain its reactivity and stability. MESP is useful because it's can relate the impacts of the total charge distribution onto electronegativity, dipole moment, partial charges, and the chemical reactivity location of the structure [39]. Different MESP values appear on the molecule's surface in the form of a colour map, with the colours ordered as Red $>$ Orange $>$ Yellow $>$ Green $>$ Blue. The colour difference represented as red on the MESP surface refers to the richest charge area, the colour difference represented as blue refers to the poorest charge region, and the colour difference described as green represents zero electrostatic potential. The strongest potential is commonly found in red regions, whereas the weakest potential is found in blue regions. MESP of PVA and PVA reacted with some metal oxides, including $\mathrm{MgO}, \mathrm{Al}_{2} \mathrm{O}_{3}, \mathrm{SiO}_{2}, \mathrm{TiO}_{2}, \mathrm{Fe}_{3} \mathrm{O}_{4}$, $\mathrm{NiO}, \mathrm{CuO}, \mathrm{ZnO}$, and $\mathrm{ZrO}_{2}$ showed in figure (5). As a result, low potential red areas are used to quantify activity. The active PVA reactivity was found to be concentrated around the $\mathrm{OH}$ group of alcohol. When 
PVA interacted with various metal oxides, the red colour spread on the up and down terminals of the polymer chain, indicating that PVA's reactivity increased, and metal oxides enhanced PVA's active sides. When PVA interacted with $\mathrm{MgO}, \mathrm{Al}_{2} \mathrm{O}_{3}, \mathrm{SiO}_{2}, \mathrm{TiO}_{2}, \mathrm{Fe}_{3} \mathrm{O}_{4}, \mathrm{NiO}, \mathrm{CuO}, \mathrm{ZnO}$, and $\mathrm{ZrO}_{2}$, low potential red regions were localised mainly around the oxygen atom of metal oxide, whereas when PVA interacted with $\mathrm{OMg}, \mathrm{O}_{3} \mathrm{Al}_{2}, \mathrm{ONi}, \mathrm{OCu}$, and $\mathrm{OZn}$, the red regions were spread across the polymer chain and increased on the other side of the chain. As a result, PVA's electrical characteristics improved, and it may now be employed in a variety field of applications.

\section{3-2 GQDs Interaction with PVA/MgO:}

PVA/MgO is the most electrically improved, stable, and active structure chosen to interact with the four GQD forms ATRI, AHEX, ZTRI, and ZHEX, according to previous studies. HOMO/LUMO orbital distributions and MESP mapping were studied also for PVA/MgO/GQDs. The TDM of PVA/MgO was 29.420 Debye, and the band gap energy $(\Delta \mathrm{E})$ was $0.330 \mathrm{eV}$. TDM, as recorded in table (2), for PVA/MgO reacted with four GQD forms altered to $59.831,30.501,14.879$, and 26.963 Debye, while band gap energy $(\Delta \mathrm{E})$ dropped to $0.273,0.318,0.201$, and 0.312 for PVA/MgO/GQD ATRI C60, PVA/MgO/GQD AHEX C42, PVA/MgO/GQD ZTRI C46 and PVA/MgO/GQD ZHEX C54, respectively. The electrical properties of the structure improved as TDM increased with decreasing band gap energy $(\Delta \mathrm{E})$, accordingly, the most electrically enhanced and stable structure is PVA/MgO/GQD ZTRI C46. Furthermore, as shown in figure (6), HOMO/LUMO orbital distributions and MESP mapping were disseminated across the GQDs sheet surface, indicating that the PVA/MgO/GQDs composition boosted the GQDs surface activity. As a result, the PVA/MgO/GQDs composite enhanced PVA sensitivity and selectivity, designed to function as a sensor.

Table 2

Optimised TDM (Debye) and $\triangle \mathrm{E}(\mathrm{eV})$ using B3LYP/LANL2DZ for PVA/MgO reinforced with GQDs

\begin{tabular}{|lll|}
\hline Structure & TDM (Debye) & $\Delta \mathrm{E}(\mathrm{eV})$ \\
\hline PVA/MgO/GQD ATRI C60 & 59.831 & 0.273 \\
\hline PVA/MgO/GQD AHEX C42 & 30.501 & 0.318 \\
\hline PVA/MgO/GQD ZTRI C46 & 14.879 & 0.201 \\
\hline PVA/MgO/GQD ZHEX C54 & 26.963 & 0.312 \\
\hline
\end{tabular}

\section{3-3 PVA/MgO/GQD as Humidity Sensor:}

As a result, the PVA/MgO/GQD ZTRI C46 composite had the greatest change in electrical characteristics. The PVA/MgO/GQD ZTRI C46 composite was chosen as a sensing material due to its unique electrical characteristics, as oversight and adjusting humidity is an important issue for many applications [40]. 
To study the PVA/MgO/GQD ZTRI C46 composite for humidity detection, 5 water molecules were subjected to interact with its surface, as shown in Figure (7). The sensing method for humidity detection, as is widely known, is based on physical characteristic changes, which TDM and HOMO/LUMO band gap energy shifts being the important sign for responsiveness [41, 42]. TDM for PVA/MgO/GQD ZTRI C46 with 5 water molecules rose from 14.879 to 21.823 Debye while band gap dropped from 0.201 to 0.188 $\mathrm{eV}$, as shown in table (3) and figure (7). This suggests that the investigated polymer composite with MO/GQD might function especially MgO nanoparticles as a humidity sensor [43], and that the presence of the MO/GQD in the composite increased the structure's reactivity and stability.

Table 3

Optimised TDM (Debye) and $\triangle E(e V)$ using B3LYP/LANL2DZ for $\mathrm{PVA} / \mathrm{MgO} / \mathrm{GQD}$ ZTRI C46 with 5 water molecules

\begin{tabular}{|lll|}
\hline Structure & TDM (Debye) & $\Delta \mathrm{E}(\mathrm{eV})$ \\
\hline PVA/ MgO/ GQD ZTRI C46+5 $\mathrm{H}_{2} \mathrm{O}$ & 21.823 & 0.188 \\
\hline
\end{tabular}

\section{4- Conclusion:}

Experimental result confirmed that $\mathrm{ZnO}$ and $\mathrm{G}$ enhanced PVA surface, so the effect of different metal oxides on PVA electronic properties were studied using molecular modeling. The electronic band gap of PVA reduced according to the addition of different metal oxides, and the behavior shifts from broadband gap to small band gap semiconductor. The addition of different metal oxides to PVA results in and controls a wide range of band gaps, opening the way for biological, solar cell, capacitor, and sensor applications. When it comes to improving electrical properties of PVA, MgO was the most efficient MO. Furthermore, the PVA/MgO/GQDs composite improved PVA sensitivity and selectivity, allowing it to act as a sensor. PVA/ MgO/ GQD ZTRI C46 composite improves PVA's potential to function as a low-cost, easily handled humidity sensor, which is critical in space applications.

\section{Declarations}

\section{5- Acknowledgements}

The authors extend their appreciation to the Scientific Research Deanship at King Khalid University and the Ministry of Education in KSA for funding this research work through the project number IFP-KKU2020/10.

Funding: (King Khalid University and the Ministry of Education in KSA for funding this research work through the project number IFP-KKU-2020/10)

Conflicts of interest/Competing interest: (N/A)

Availability of data and material: (N/A) 
Code availability: (N/A)

Authors' contributions: (Dr. Maroof A. Hegazy wrote the result and discussion, Hend A. Ezzat calculated the model structures, Prof. Ibrahim S. Yahia revised the manuscript, Prof. Heba Y. Zahran wrote the introduction section Prof. Hanan Elhaes contribute in the result and discussion writing, Ms Hanan Matar carry out the XRD results and discussion and Prof. Medhat A. Ibrahim revised the manuscript and submitted it for publication)

\section{References}

1. Adhikari B, Majumdar S (2004) Polymers in sensor applications. Prog Polym Sci 29:699-766. https://doi.org/10.1016/j.progpolymsci.2004.03.002

2. Ningaraju S, Prakash AG, Ravikumar HB (2018) Studies on free volume controlled electrical properties of PVA/NiO and PVA/TiO 2 polymer nanocomposites. Solid State lon 320:132-147. https://doi.org/10.1016/j.ssi.2018.03.006

3. Thangamani JG, Deshmukh K, Sadasivuni KK, Ponnamma D, Goutham S, Rao KV, Chidambaram K, Ahamed MB, Grace AN, Faisal M, Pasha SK (2017) White graphene reinforced polypyrrole and poly (vinyl alcohol) blend nanocomposites as chemiresistive sensors for room temperature detection of liquid petroleum gases. Mikrochim Acta 184:3977. https://doi.org/10.1007/s00604-017-2402-1

4. Abdullah OG, Salman YA, Tahir DA, Jamal GM, Ahmed HT, Mohamad AH, Azawy AK (2021) Effect of $\mathrm{ZnO}$ nanoparticle content on the structural and ionic transport parameters of polyvinyl alcohol based proton-conducting polymer electrolyte membranes. Membranes 11:163. https://doi.org/10.3390/membranes 11030163

5. Aziz MF, Azam MA, Noor IM, Buraidah MH, Arof AK (2021) Impact of Diethyl carbonate in PVA based gel polymer electrolytes on dye-sensitized solar cells performance. Opt Quantum Electron 53:1-16. https://doi.org/10.1007/s11082-020-02724-8

6. Nangia R, Shukla NK, Sharma A (2019) Optical and structural properties of Se80Te15Bi5/PVA nanocomposite films. J Mol Struct 1177:323-330. https://doi.org/10.1016/j.molstruc.2018.09.080

7. Camargo PHC, Satyanarayana KG, Wypych F (2009) Nanocomposites: synthesis, structure, properties and new application opportunities. Mater Res 12:1-39. https://doi.org/10.1590/S151614392009000100002

8. Davar F, Majedi A, Mirzaei A (2018) Polyvinyl alcohol thin film reinforced by green synthesized zirconia nanoparticles. Ceram Int 44:19377-19382. https://doi.org/10.1016/j.ceramint.2018.07.167

9. Costa ACS, Alves HPA, Correa MA, Bohn F, Acchar W (2019) Iron oxide/PVA flexible magnetic tape engineered by microwave combustion and tape casting. Mater Chem Phys 232:1-5. https://doi.org/10.1016/j.matchemphys.2019.04.027

10. Hadi A, Hashim A, Al-Khafaji Y (2020) Structural, optical and electrical properties of PVA/PEO/SnO 2 new nanocomposites for flexible devices. Trans Electr Electron Mater 21:283-292. https://doi.org/10.1007/s42341-020-00189-w 
11. Hashim A, Al-Khafaji Y, Hadi A (2019) Synthesis and characterization of flexible resistive humidity sensors based on PVA/PEO/CUO nanocomposites. Trans Electr Electron Mater 20:530-536. https://doi.org/10.1007/s42341-019-00145-3

12. Jebur QM, Hashim A, Habeeb MA (2019) Structural, electrical and optical properties for (polyvinyl alcohol-polyethylene oxide-magnesium oxide) nanocomposites for optoelectronics applications. Trans Electr Electron Mater 20:334-343. https://doi.org/10.1007/s42341-019-00121-x

13. Ibrahim MA, Gawad AEDA (2012) Spectroscopic analyses of chitosan interactions with amino acids. J Comput Theor 9:1120-1124. https://doi.org/10.1166/jctn.2012.2154

14. Refaat A, Ibrahim MA, Elhaes H, Badry R, Ezzat H, Yahia IS, Zahran HY, Shkir M (2019) Geometrical, vibrational and physical properties of polyvinyl chloride nanocomposites: Molecular modeling approach. J Theor Comput Chem 18:1950037. https://doi.org/10.1142/S0219633619500378

15. Ibrahim M (2009) Molecular modeling and FTIR study for $\mathrm{K}, \mathrm{Na}, \mathrm{Ca}$ and $\mathrm{Mg}$ coordination with organic acid. J Comput Theor Nanosci 6:682-685. https://doi.org/10.1166/jctn.2009.1094

16. Ezzat HA, Hegazy MA, Nada NA, Osman O, Ibrahim MA (2021) Development of natural polymer/metal oxide nanocomposite reinforced with graphene oxide for optoelectronic applications. NRIAG J Astron Geophys 10:10-22. https://doi.org/10.1080/20909977.2020.1846246

17. Hegazy MA, Ghoneim R, Ezzat HA, Yahia IS, Elhaes H, Ibrahim MA (2021) Electronic and physical studies for Teflon FEP as a thermal control in low earth orbit reinforced with $\mathrm{ZnO}$ and $\mathrm{SiO} 2$ nanoparticles. J Mol Model 27:1-8. https://doi.org/10.1007/s00894-021-04912-z

18. Menazea AA, Ezzat HA, Omara W, Basyouni OH, Ibrahim SA, Mohamed AA, Tawfik W, Ibrahim MA (2020) Chitosan/graphene oxide composite as an effective removal of $\mathrm{Ni}, \mathrm{Cu}, \mathrm{As}, \mathrm{Cd}$ and $\mathrm{Pb}$ from wastewater. Comput Theor Chem 1189:112980. https://doi.org/10.1016/j.comptc.2020.112980

19. Badry R, Radwan SH, Ezzat D, Ezzat H, Elhaes H, Ibrahim M (2020) Study of the Electronic Properties of Graphene Oxide/(PANi/Teflon). Biointerface Res Appl Chem 10:6926-6935. https://doi.org/10.33263/BRIAC106.69266935

20. Badry R, Ibrahim A, Gamal F, Shehata D, Ezzat H, Elhaes H, Ibrahim M (2020) Electronic Properties of Polyvinyl Alcohol/TiO2/SiO2 Nanocomposites. Biointerface Res Appl Chem 10:6427-6435. https://doi.org/10.33263/BRIAC105.64276435

21. Ibrahim M (2020) Modeling the Effect of Zinc Oxide on the Electronic Properties of Polyvinyl Alcohol. Egypt J Chem 63:3-5. https://doi.org/10.21608/ejchem.2020.27245.2564

22. Ibrahim M, Osman $O$ (2009) Spectroscopic analyses of cellulose: Fourier transform infrared and molecular modelling study. J Comput Theor Nanosci 6:1054-1058. https://doi.org/10.1166/jctn.2009.1143

23. Gomaa F, Osman O, Ezzat H, Ibrahim M (2016) Molecular spectroscopic analyses of soil close to Nile Delta region. Quantum Matter 5:263-267. https://doi.org/10.1166/qm.2016.1298

24. Ahmed H, Abduljalil HM, Hashim A (2019) Structural, optical and electronic properties of novel (PVA$\mathrm{MgO} / \mathrm{SiC}$ nanocomposites films for humidity sensors. Trans Electr Electron Mater 20:218-232. https://doi.org/10.1007/s42341-019-00111-z

Page $10 / 19$ 
25. Ahmed H, Hashim A (2021) Geometry optimization, optical and electronic characteristics of novel PVA/PEO/SiC structure for electronics applications. Silicon 13:2639-2644. https://doi.org/10.1007/s12633-020-00620-0

26. Kumar YR, Deshmukh K, Ali MMN, Abhijay G, Al-Onazi WA, Al-Mohaimeed AM, Pasha SK (2022) Structure, morphology and modelling studies of polyvinylalcohol nanocomposites reinforced with nickel oxide nanoparticles and graphene quantum dots. Environ Res 203:111842. https://doi.org/10.1016/j.envres.2021.111842

27. Lee C, Yang W, Parr RG (1988) Development of the Colic/Salvetti correlation/energy formula into a functional of the electron density. Phys Rev B 37:785

28. Becke AD (1993) Density/functional thermochemistry. III. The role of exact exchange. J Chem Phys 98:5648-5652

29. Vosko SH, Wilk L, Nusair M (1980) Accurate spin/dependent electron liquid correlation energies for local spin density calculations: a critical analysis. J Phys 58:1200-1211

30. Frisch MJ, Trucks GW, Schlegel HB, Scuseria GE, Robb MA, Cheeseman JR, Scalmani G, Barone V, Mennucci B, Petersson GA, Nakatsuji HM, Caricato, Li X, Hratchian HP, Izmaylov AF, Bloino J, Zheng G, Sonnenberg JL, Hada M, Ehara M, Toyota K, Fukuda R, Hasegawa J, Ishida M, Nakajima T, Honda Y, Kitao O, Nakai H, Vreven T, Montgomery JA Jr, Peralta JE, Ogliaro F, Bearpark M, Heyd JJ, Brothers E, Kudin KN, Staroverov VN, Keith T, Kobayashi R, Normand J, Raghavachari K, Rendell A, Burant JC, lyengar SS, Tomasi J, Cossi M, Rega N, Millam JM, Klene M, Knox JE, Cross JB, Bakken V, Adamo C, Jaramillo J, Gomperts R, Stratmann RE, Yazyev O, Austin AJ, Cammi R, Pomelli C, Ochterski JW, Martin RL, Morokuma K, Zakrzewski VG, Voth GA, Salvador P, Dannenberg JJ, Dapprich S, Daniels AD, Farkas O, Foresman JB, Ortiz, J.V., Cioslowski, J., Fox, D.J., Gaussian 09, Revision C.01, Gaussian, Inc., Wallingford, CT, (2010)

31. Kumaraswamy S, Babaladimath G, Badalamoole V, Mallaiah SH (2017) Gamma irradiation synthesis and in vitro drug release studies of ZnO/PVA hydrogel nanocomposites. Adv Mater Lett 8:02-07. https://doi.org/10.5185/amlett.2017.6819

32. Gupta S, Webster TJ, Sinha A (2011) Evolution of PVA gels prepared without crosslinking agents as a cell adhesive surface. Journal of Materials Science: Materials in Medicine 22:1763-1772. https://doi.org/10.1007/s10856-011-4343-2

33. Kumar A, Negi YS, Bhardwaj NK, Choudhary V: Synthesis and characterization of cellulose nanocrystals/PVA based bionanocomposite. Adv. Mater. Lett, 4,626-631 (2013) Adv. Mat. Lett. 4, 626-631 (2013). https://doi.org/10.5185/amlett.2012.12482

34. Singh RP, Shukla VK, Yadav RS, Sharma PK, Singh PK, Pandey AC (2011) Biological approach of zinc oxide nanoparticles formation and its characterization. Adv Mater Lett 2:313-317. https://doi.org/10.5185/amlett.indias.204

35. Kondawar SB, Acharya SA, Dhakate SR (2011) Microwave assisted hydrothermally synthesized nanostructure zinc oxide reinforced polyaniline nanocomposites. Adv Mat Lett 2:362-367. https://doi.org/10.5185/amlett.2011.9107am2011 
36. Hashim A, Hadi A (2017) Synthesis and characterization of (MgO- Y2O3-CuO) nanocomposites for novel humidity sensor application. Sens Lett 15:858-861. https://doi.org/10.1166/sl.2017.3900

37. Zhang Z, Zhang J, Chen N, Qu L (2012) Graphene quantum dots: an emerging material for energy/related applications and beyond. Energy Environ Sci 5:8869-8890. https://doi.org/10.1039/C2EE22982JJ

38. Feng H, Dong B, Pang Y, Chen L, Yu L, Dong (2019) Tuning the electronic and optical properties of graphene quantum dots by selective boronization. J Mater Chem C 7:237-246. https://doi.org/10.1039/C8TC03863E

39. Lu T, Chen Q: van der Waals potential: an important complement to molecular electrostatic potential in studying intermolecular interactions Mol J (2020) Model 26:1-9. https://doi.org/10.1007/s00894020-04577-0

40. Ezzat HA, Hegazy MA, Nada NA, Osman O, Ibrahim MA (2020) Application of natural polymers enhanced with $\mathrm{ZnO}$ and $\mathrm{CuO}$ as humidity sensor. NRIAG J Astron Geophys 9:586-597. https://doi.org/10.1080/20909977.2020.1821573

41. Ibrahim M, El-Haes H (2005) Computational spectroscopic study of copper, cadmium, lead and zinc interactions in the environment. Int J Environ Pollut 23:417-424

42. Ibrahim M, Mahmoud AA (2009) Computational notes on the reactivity of some functional groups. J Comput Theor Nanosci 6:1523-1526. https://doi.org/10.1166/jctn.2009.1205

43. Gandhi S, Abiramipriya P, Pooja N, Jeyakumari JJL, Arasi AY, Dhanalakshmi V, Anbarasan R (2011) Synthesis and characterizations of nano sized $\mathrm{MgO}$ and its nano composite with poly(vinyl alcohol). J Non-Cryst Solids 357:181-185. https://doi.org/10.1016/j.jnoncrysol.2010.09.050

\section{Figures}




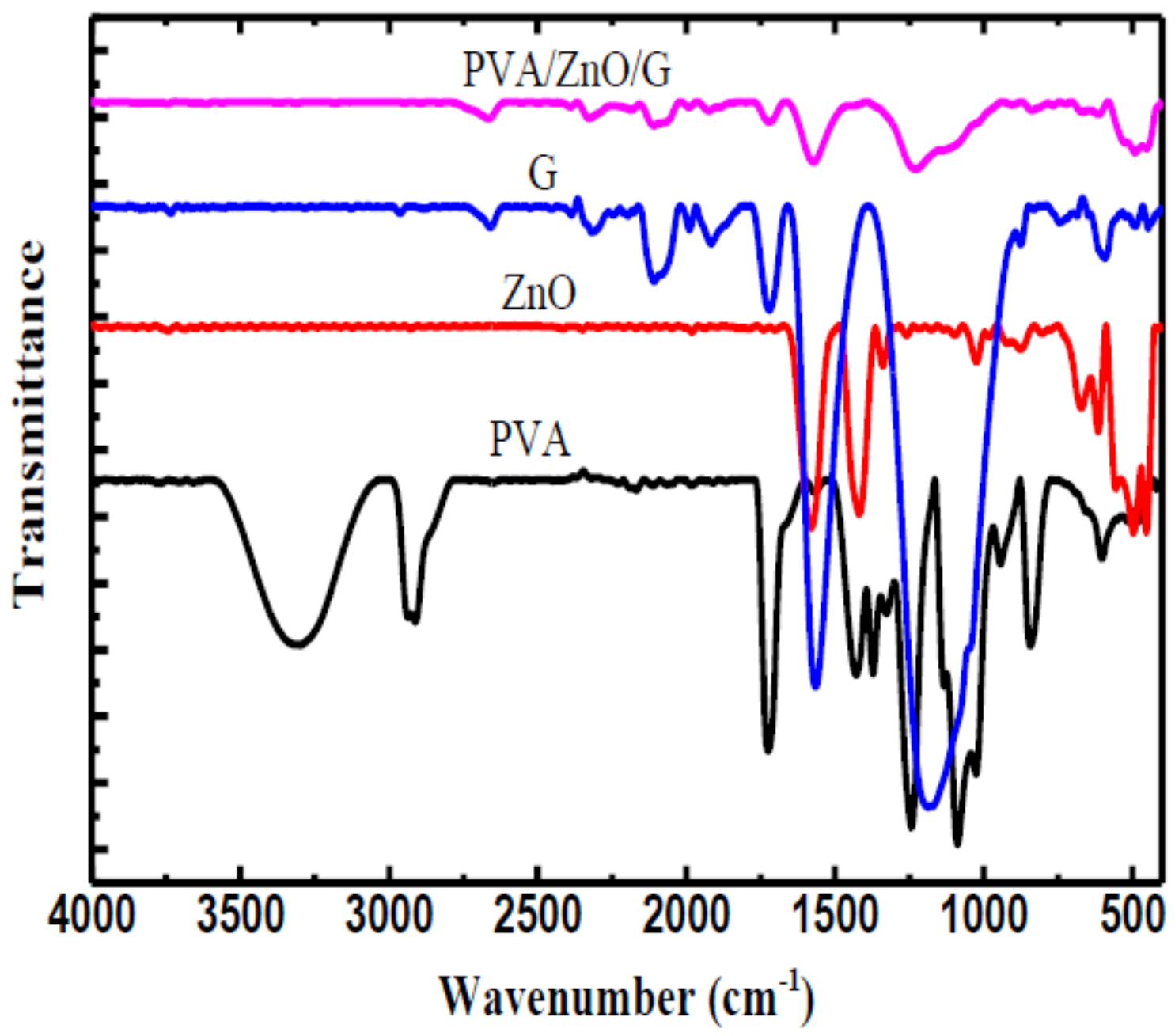

Figure 1

ATR-FTIR transmittance spectra for the studied PVA, ZnO, G and PVA/ZnO/G nanocomposite. 


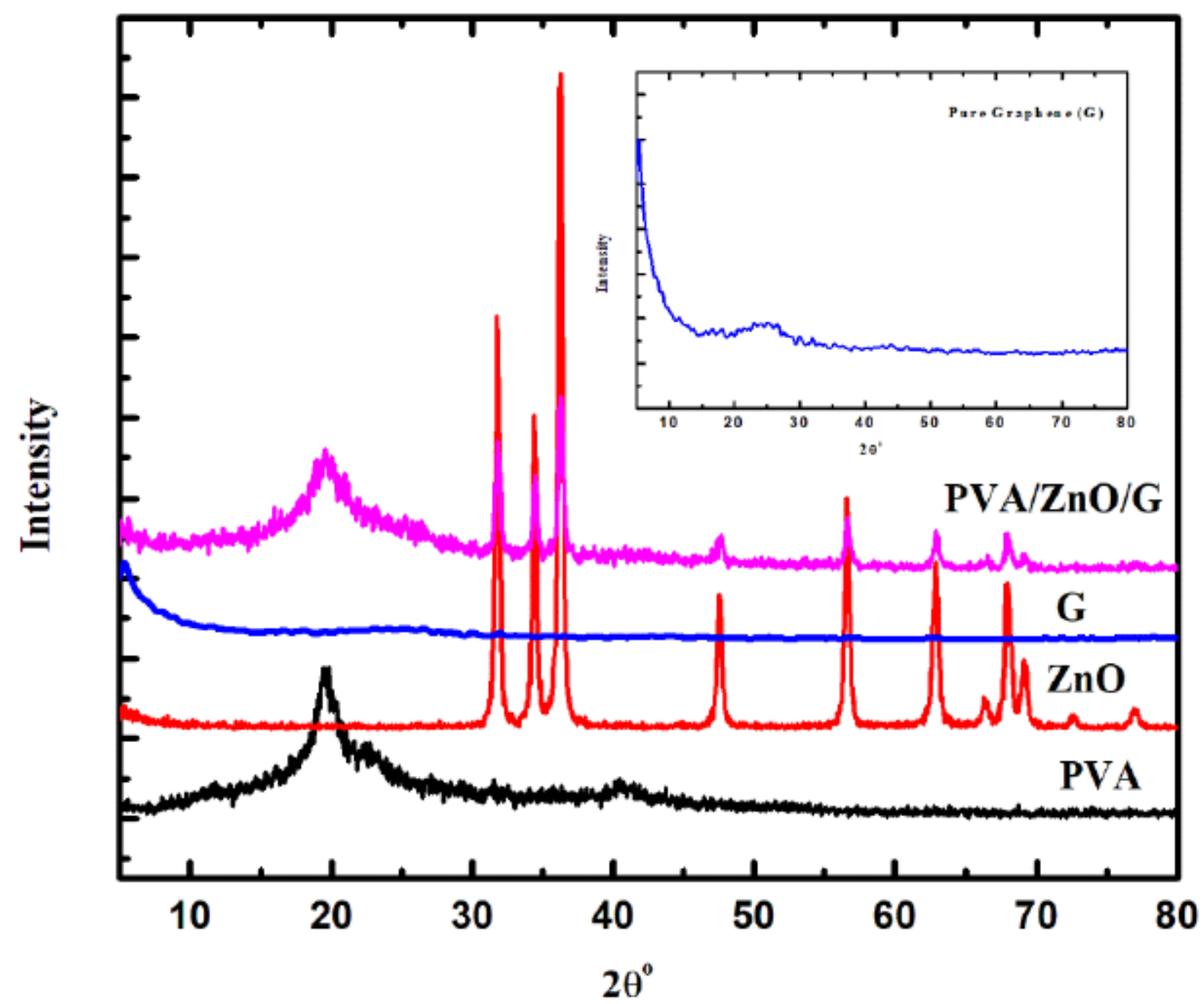

Figure 2

XRD diffraction pattern for PVA, ZnO, G and PVA/ZnO/G nanocomposite. 


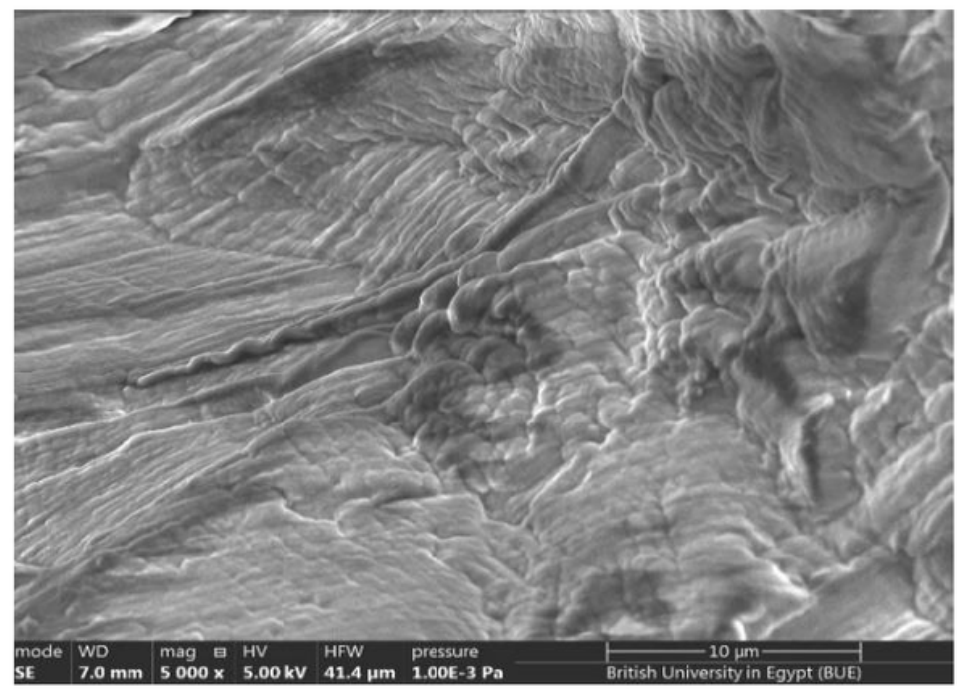

PVA

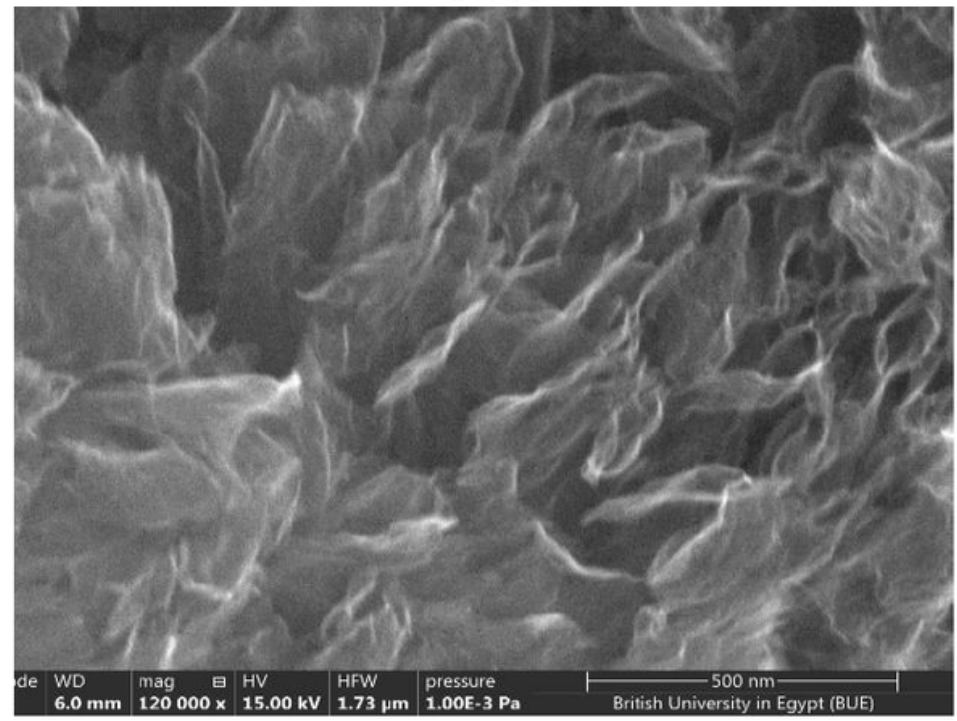

G

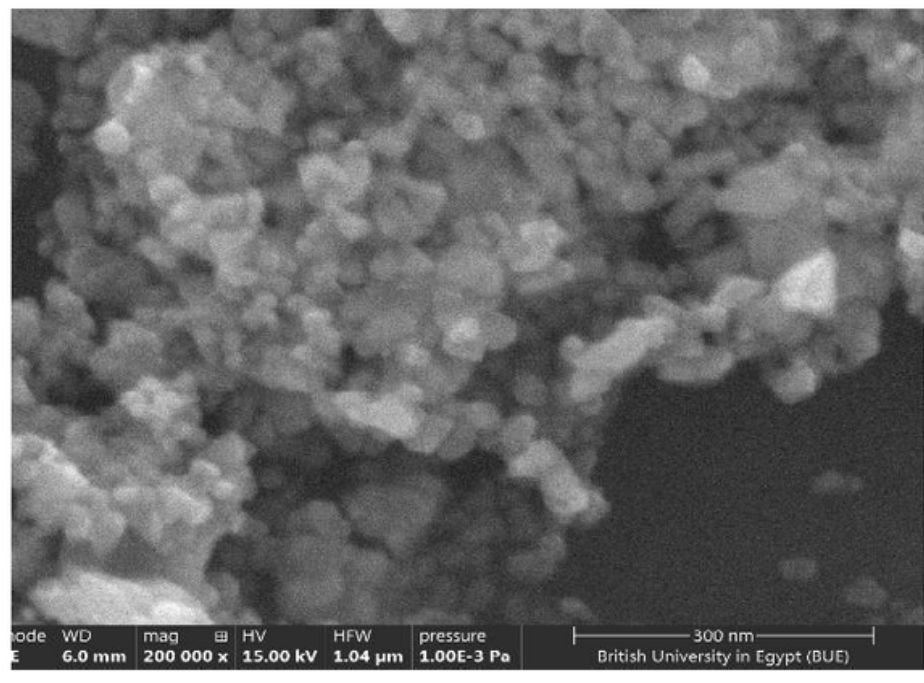

$\mathrm{ZnO}$

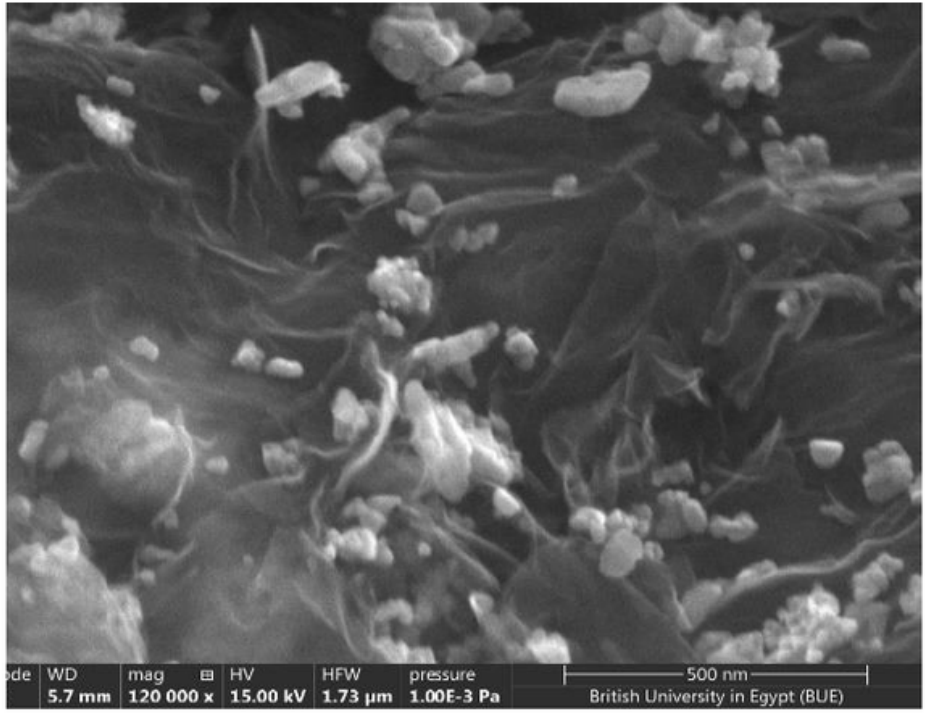

$\mathrm{PVA} / \mathrm{ZnO} / \mathrm{G}$

\section{Figure 3}

FESEM of PVA, ZnO, G and PVA/ZnO/G powder samples 


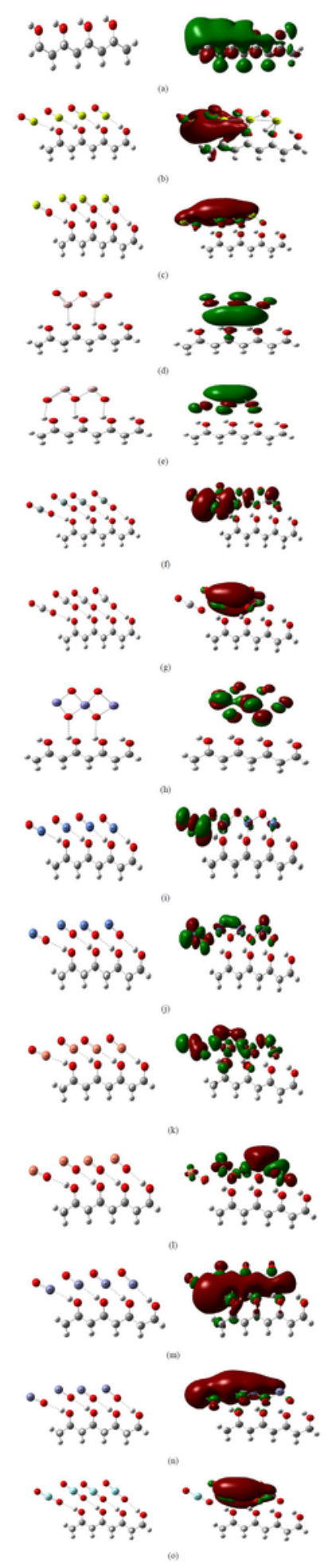

\section{Figure 4}

Optemized structure and DFT:B3LYP/LANL2DZ HOMO/LUMO orbital distrbution calculations of PVA and PVA interacted with different metal oxides of as (a) PVA (b) PVA/MgO (c) PVA/OMg (d) PVA/Al2O3 (e) PVA/ O3Al2 (f) PVA/SiO2 (g) PVA/TiO2 (h) PVA/ Fe3O4 (i) PVA/NiO (j) PVA/ONi (k) PVA/CuO (l) PVA/OCu (m) PVA/ZnO (n) PVA/OZn (o) PVA/ ZrO2 
(a)

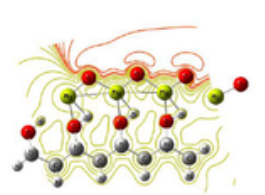

(b)

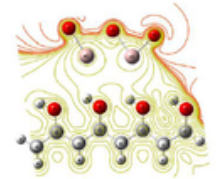

(d)

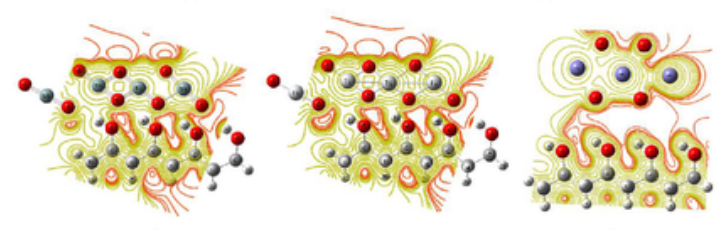

(f)

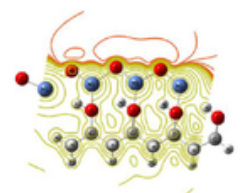

(i)
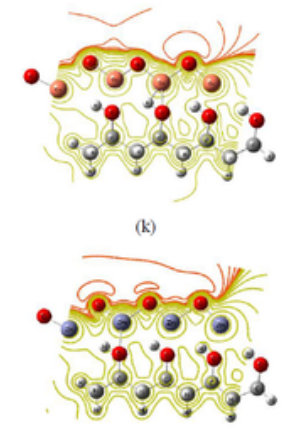

(m)

(g)

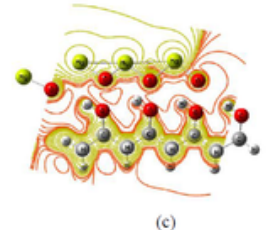

(c)

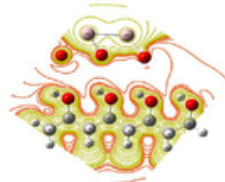

(e)

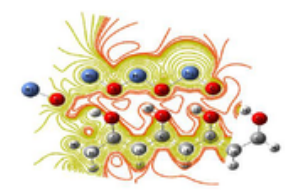

(j)

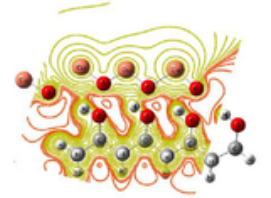

(I)

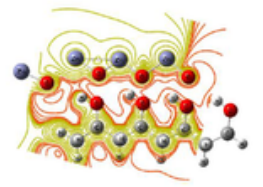

(n)

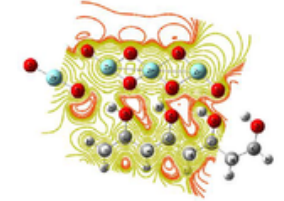

(o)

\section{Figure 5}

DFT:B3LYP/LANL2DZ MESP mapping calculations of PVA and PVA interacted with different metal oxides as (a) PVA (b) PVA/MgO (c) PVA/OMg (d) PVA/Al2O3 (e) PVA/ O3Al2 (f) PVA/SiO2 (g) PVA/TiO2 (h) PVA/ Fe3O4 (i) PVA/NiO (j) PVA/ONi (k) PVA/CuO (I) PVA/OCu (m) PVA/ZnO (n) PVA/OZn (o) PVA/ ZrO2 


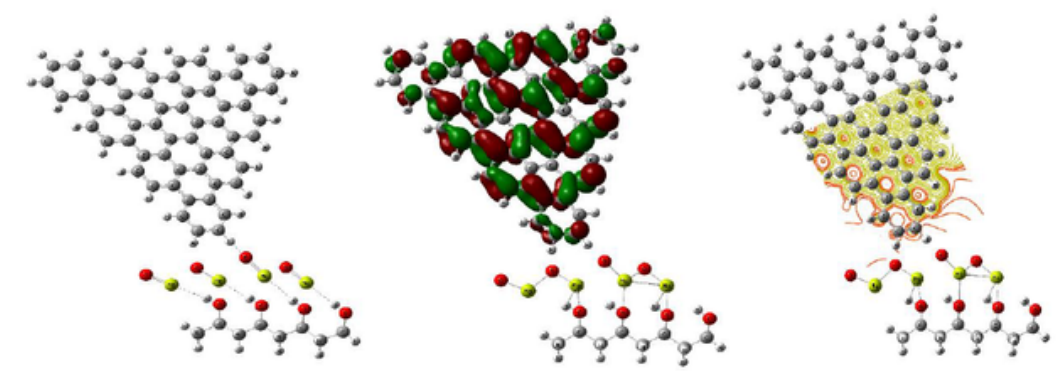

(a)

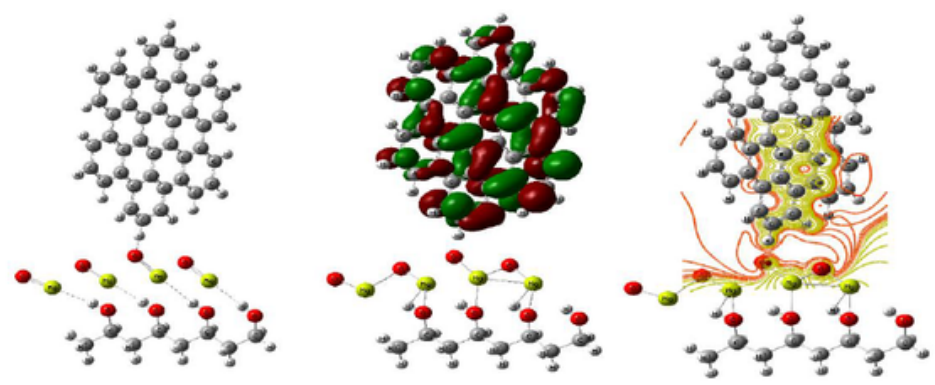

(b)
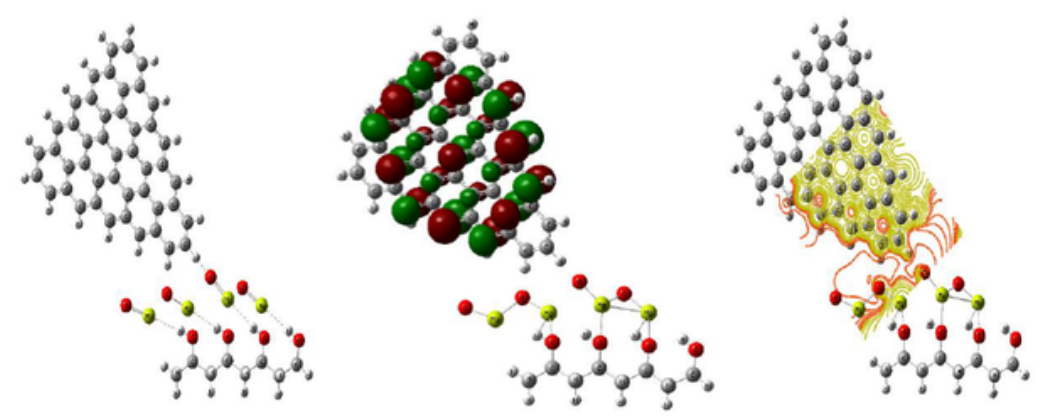

(c)
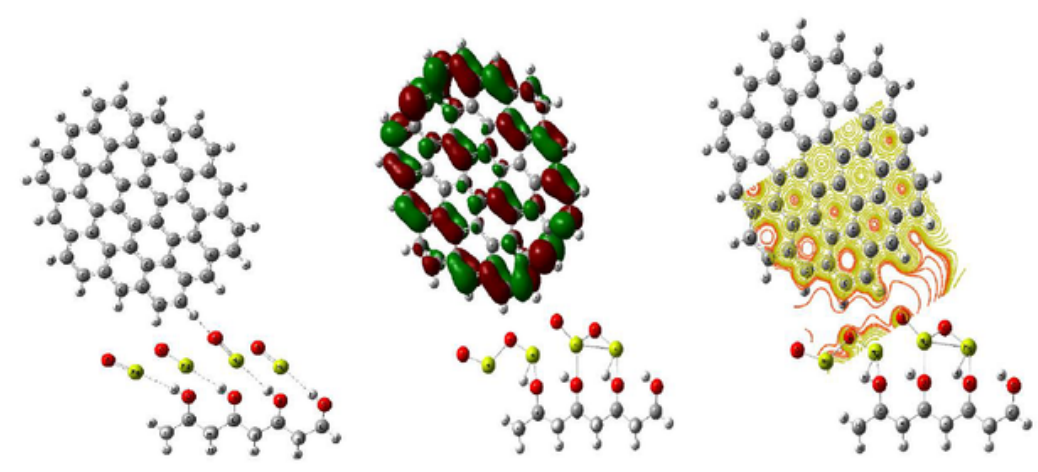

(d)

Figure 6

Optemized structure and DFT:B3LYP/LANL2DZ HOMO/LUMO orbital distrbution and MESP mapping calculations of PVA/MgO reinforced with GQDs as (a) PVA/MgO/GQD ATRI C60 (b) PVA/MgO/GQD AHEX C42 (c) PVA/MgO/GQD ZTRI C46 (d) PVA/MgO/GQD ZHEX C54 

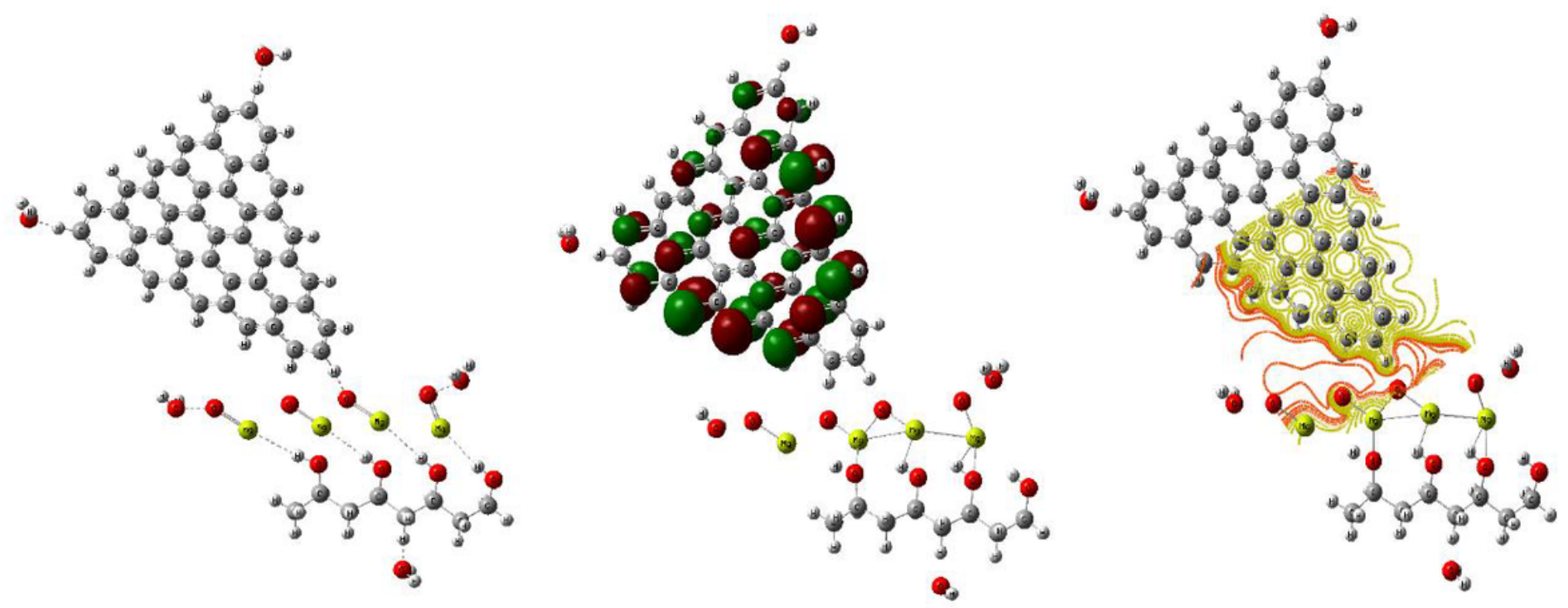

Figure 7

Optemized structure and DFT:B3LYP/LANL2DZ HOMO/LUMO orbital distrbution and MESP mapping calculations of PVA/ MgO/ GQD ZTRI C46 with 5 water molecules. 